\title{
Water Balance ixa Goats Maintained Under Mild and Hot Weather
}

\author{
K. H. Taymozr, G.A.R. Kamar, H. A. Gabr and K. M. \\ El-Masry
}

Atomic Energy Establishment and Faculty of Agriculture, Cairo and Zagazig Universities, Egypt.

HEAT STRESS increased the total body water of goats from 12.42 $(\mathrm{P}<0.01)$ to $13.07 \pm 1.21 \mathrm{~L}$. This increase was significant at body weight increased also signifently as percentage of live $18^{\circ}$ to $68.26 \pm 1.92$ at $380^{\circ}$.

increased body watcr expressed as percentage of total body solids, $222.75+25.32$ at $38^{\circ}$.

The average of TBS in goats $7.29 \pm 0.92$ decreased signiwere expressed as percontage of $6.32 \pm 0.91 \mathrm{~kg}$. When the values $36.60+1.80$ decreased significantly $(\mathbb{P}<0.0 \mathrm{~g})$ the averages were at $18^{\circ}$ and $28^{\circ}$, respectively.

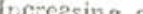

WTR significantly $(\mathrm{P}<0.01)$ from fic $\mathrm{m} 18^{\circ}$ to $38^{\circ}$ increased When the values of W were $83.30+6.79$ at 180 were expressed as $\mathrm{mil} / \mathrm{kg}$ LBW/ day, they at $38^{\circ}$. WTR, expressed as ml/kg $82^{\circ} \%$ ificantly to $143.29 \pm 9.69$ cantly from $140.82+8.92$ at $182 \%$ diay, increased also signifi-

$240.46 \pm 16.97$ at $38^{\circ}$.

$(P<0.01)$ from $5.42+0.42$ at $<$ trited water decreased significantiy $38^{\circ}$. The decrease in $71 / 2$ under ho $18^{\circ}$ to $3.37 \pm 0.20$ days at of increased water intake and water conditions was the resuit

was studied, however, goats maintained under mild climate (180) $0.13 \pm 0.00$ wever, total water intake consisice of $1.47 \pm 0.03$, water and feed water, $0.54 \pm 0.01,0.50+0.03,0.27+0.02$ Toss consisted of for urinary water fecal water, respizatery 0.02 and $0.35 \pm 0.05$, loss, respectively.

When values of water balance were expressed as percentages of total water intake, the averages were $87.95+0.31,7.73$ 0.16 and $4.27 \pm 0.28$ for free water $87.95 \pm 0.31,7.73 \pm$ water, respectively and $32.6 \pm 1.02,29.91 \pm 2.69,16.66 \pm$ 1.60 and $20.86 \pm 2.97$ for urinary, fecal, respiratory and skjn
water loss, respectively. 


\begin{abstract}
When the components of water balance at $38^{\circ}$ were expressed as percentages of daily water in take the averages were $93.25 \pm 1.78$, $4.57 \pm 0.29$ and $2.16 \pm 0.31$ for free, metabolic and feed water. Those for urinary, fecal, respiratory, skin swater loss and water retention were $36.48 \pm 4.83,12.03 \pm 1.73,23.58 \pm$ 4.42 and $22.12 \pm 2.70$ and $4.38 \pm 0.13$ respectively. significant differences were found between the $18^{\circ}$ and $38^{\circ}$ and $38^{\circ}$ water balance values. At $18^{\circ}$, the goats were in steady state concerning the live body weight and the physiology of water bala. nce, assumed that total water loss equal with total water inake.
\end{abstract}

When the goats were exposed to $38^{\circ}$, the retained water took place in water balance then the goats had a positive water balance.

Water metabolism is of a prime importance for animal productivity because water plays a big role in heat regulation particularly under hot desert conditions beside its importance in carrying out the biochemical reactions for all
vital activities.

In Egypt, the desert represents $96 \%$ of the Egyptian territory and in such desert, the few existing livestock animals walk for distances looking for watering, which may take 3-7 days each time Apparently water in such areas becomes a limiting factor for the expansion in animal production. It is desirable to select for these areas, where water costs more than feed, species, breeds and animals within breeds, most efficient in water economy, which require little amounts of water for maximum milk and meet production.

The objective in this study was to determine all components of water metabolism in goats under controlled mild and hot climates in the climatic chambers using the different tracer techniques. Besides, the heat tolerance index using the TOH tracer technique was used to determine the variability
between goats in heat tolerance.

\title{
Material and Methods
}

Six male goats were used in the present study. They were $2.5-3$ years old, their weights ranged from $19-25 \mathrm{~kg}$. The animals were kept outdoors under open shed before starting the experiment. They were fed on $500 \mathrm{~g}$ concentrates, $500 \mathrm{~g}$ clover hay and $250 \mathrm{~g}$ wheat straw daily through the experimental period. The concentrates which were in the form of pellets, consisted of undecorticated cotton seec cake $60 \%$, wheat bran $10 \%$, rice milling $25 \%$, lime stone $2 \%$, sodium chloride $1 \%$ and molasses $2 \%$. The goats were watered three times daily ad libitum by buckets.

The experiments on goats were conducted in the climatic chamber of the Tracer Bioclimatology Unit of the ARE USA-NSF Project "Bovine Adaptation to the Sahara" of the Atomic Energy Authority. It was provided with a 7.5 ton air cooled conditioning system, that can regulate the temperature tively. A thermohygrograph $50^{\circ}$ and between $80 \%$ and $20 \%$ R.H., respecperature and humidity.

Egypt. J. Anim. Prod. 24, No. 1-2 (1984) 


\section{B. Experimental design and Statistical analysis}

Six male goats, were used in the present study

ned in the climatic chamber in the present study. The goats were maintai$65 \%$ R.H. followed by 7 days, 7 hr daly 7 days, 7 hours daily at $18^{\circ}$ and of temperature in climatic chamber hr daily at $38^{\circ}$ and $50 \%$ R.H. The raise point $\left(38^{\circ}\right)$ of temperature through gradually and reached to the maximum weight measurements were carried one hour. During such time live body and on 7 th days in each of mild and hot climates.

The components

cilution and the conventional technism were determined by the TOH which were measured consisted of total The physiological parameters biological half life time of TOH, total botal body water, water turnover rate, Milk and urine samples were used for total body heat tolerance coefficient. rate determinations by extrapolation tectal body water and water turnover averages of the two treatments were tested bye. The differences between the cance, according to Snedecor and Cochran (1967)

water output were detcrmined and calculation of results water intake and (1983). Tracer technique was described and reviewed after Taymour et al. coefficient (HTC) based on the estied out for estimation of heat tolerance mild and hot climates. The pstimation of total body solids (TBS) under due to heat exposure was subtracted fre decrease in total body solids content tolerance as described by Kamal from 100 to obtain the coefficient of heat body solids estimated by live body weight in each of climatic the total body water (TBW) from the TBS, HTC is as follows:

TBS, $\mathrm{HTC}=\frac{100-\mathrm{TBS} \% \text { at } 18^{\circ}-\mathrm{TBS} \% \text { at } 38^{\circ}}{\mathrm{TBS} \% \text { at } 18^{\circ}} \times 100$

\section{Results and Discussion}

Data presented in Table 1 showed that at $18^{\circ}$ for $7 \mathrm{hr}$ daily, total water intake as $L /$ day consisted of $1.47 \pm 0.03,0.13 \pm 0.00$ and $0.07 \pm 0.00$ for
free, metabolic and feed water, respectively, of $0.54 \pm 0.01,0.50+0.03,0.27 \pm 0.02$ and total water output consisted for urinary, fecal, respiratory and skin \pm 0.02 and $0.35 \pm 0.05$, respectively, equaled the total water output and averaged loss. Total water intake, however

When the values of water $1.67 \pm 0.04 \mathrm{~L} /$ day.

the averages for water intake componce were expressed as $\mathrm{ml} / \mathrm{kg} \mathrm{LBW} / \mathrm{day}$, and $3.43+0.23$, respectively, for frents were $71.06 \pm 6.05,5.26+0.58$ was $80.76+6.80$. In this free metabolic and feed water and the total $26.11 \pm 1.77,23.50+0.72,13.61+$ In tively, for urinary, fecal, respiratory and 2.07 and $17.64 \pm 3.44$, respec$80.76 \pm 6.80$ as shown in Table 1 .

Egypt. J. Anim. Prod. 24, No. 1-2 (1984) 
When the values were expressed as percentages of daily water intake, the averages were $87.95 \pm 0.31,7.73 \pm 0.16$ and $4.27 \pm 0.28$, respectively, for free, metabolic and feed water and those for urinary, fecal, respixatory and skin water loss were $32.56 \pm 2.97$, respectively as shown in Table 1 .

TABLE 1: Water balance as 1/day, mil/kg LBW/day and as percent of daily water intake in goats maintained under mild weather.

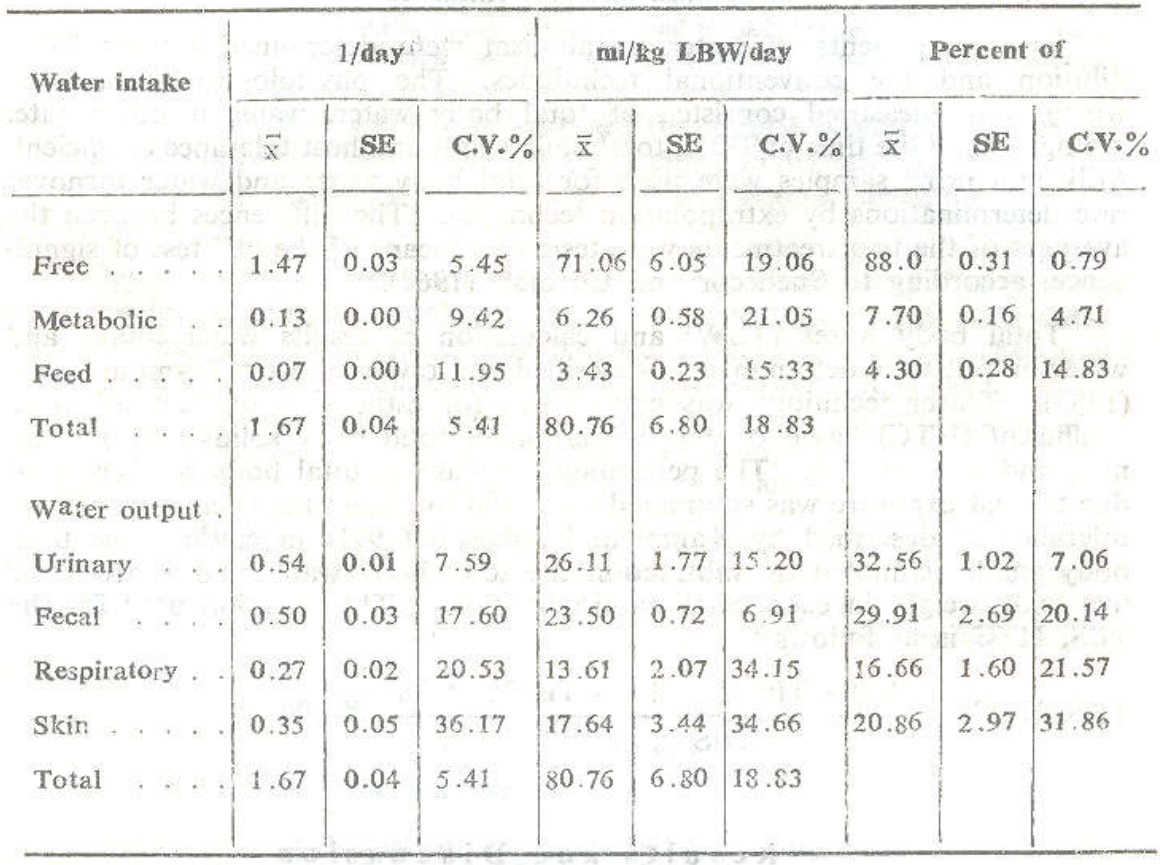

When ambient temperature was increased to $38^{\circ}$ for $7 \mathrm{hr}$ daily there was an apparent increase in each of water intake and water output components, where, they averaged $2.58 \pm 0.07,0.12,0.06 \mathrm{~L} /$ day for free, metabolic and feed water, respectively, and $1.06 \pm 0.14,0.33 \pm 0.05,0.64 \pm 0.1$ and $0.60 \pm 0.07 \mathrm{~L} /$ day, respectively, for urinary, fecal, respiratory and skin water output (Table 3 ). The difference between total water intake and total water output represents the increase in total body water or water retained in the goat's body amounting to $0.12 \mathrm{~L} /$ day. Water balance, expressed as $\mathrm{ml} / \mathrm{kg}$ $\mathrm{LBW} /$ day at $38^{\circ}$ averaged $134.52 \pm 9.84,125.31 \pm 8.67,6.20 \pm 0.69$ and $3.01 \pm 0.60$, respectively, for total, free, metabolic and feed water, whereas, the water output averaged $128.62 \pm 9.42,51.46 \pm 7.20,16.10 \pm 2.46$, $31.73 \pm 6.33$ and $29.31 \pm 3.53$, respectively, for total, urinary, fecal, respiratory and skin water loss (Table 2).

Egypt. J. Anim. Prod. 24, No. 1-2 (1984) 
Data presented in Table 2 revealed that the components of water intake and output expressed as percentages of daily water intake were $93.25 \pm 1.78$, $4.57 \pm 0.2$ and $2.16 \pm 0.31$ for free water metabolic water and feed water, respectively and skin water loss were $36.48 \pm 4.83,12.03 \pm 1.73,23.58 \pm$ 4.42 and $22.12 \pm 2.70$, respectively.

It can be noted that the average of water retention as percent of total water intake at $38^{\circ}$ was $4.38 \pm 0.13$, then the animals had a positive water balance under high temperature. The significant differences $(\mathrm{P}<0.01)$ were found between the $18^{\circ}$ and $38^{\circ}$ water balance values (Table 2 ).

TABLE 2. Water balance as $1 /$ day, $\mathrm{ml} / \mathrm{kg} \mathrm{LBW}$ day and as percent of daily water intake in goats maintained under hot climete for $7 \mathrm{hr}$ daily.

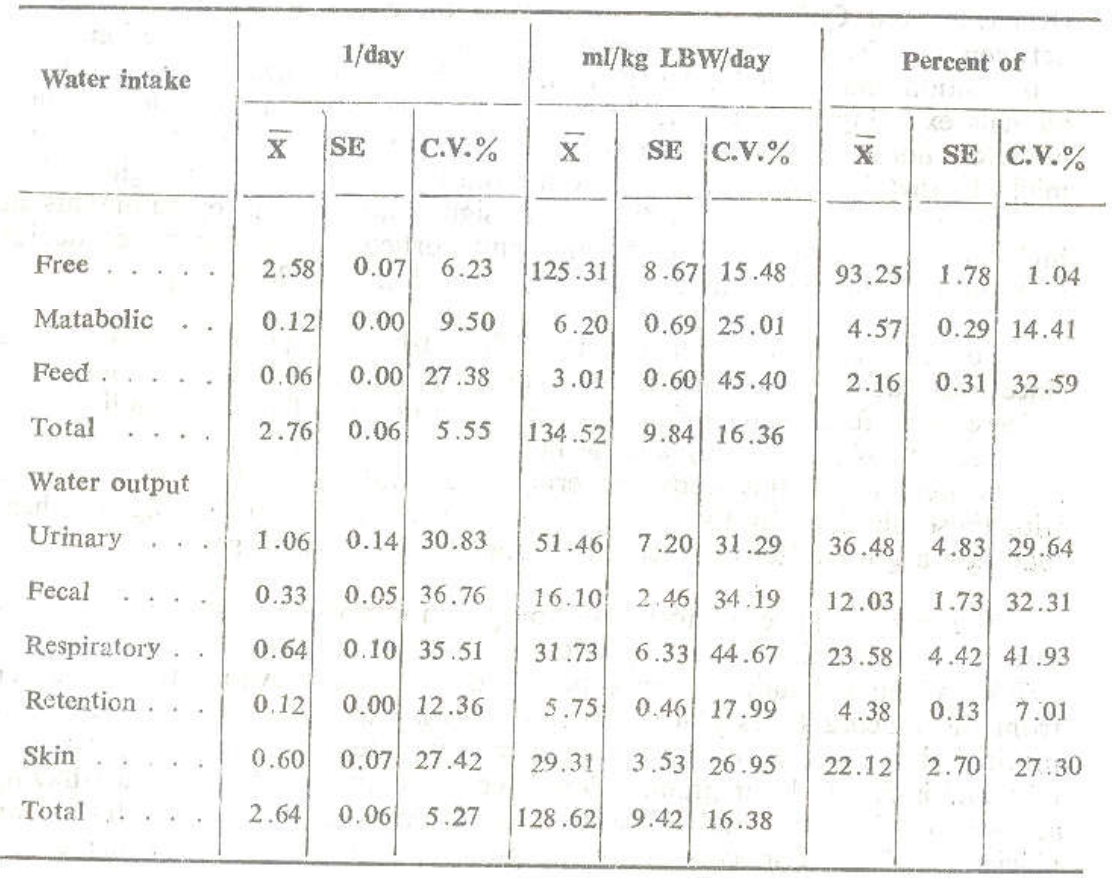

It is worthnoting, that the increase in total water intake under high environmental temperature in the present study is in accordance with other studies in different ruminants (Kamal et al., 1962 ; Roy et al., 1964 ; Maloiy, 1972 ; Kellaway and Colditz, 1975).

Egypt. J. Anim. Prod. 24, No. 1-2 (1984) 
The mechanism responsible for heat-induced increase in water consumption has been suggested by Kamal et al. (1962). They stated that the increase in ambient temperature caused significant increase in water output through urine and vaporization in ruminants. Such water output would cause a temporary body water deficit with resultant increase concentration of body fuids (extracellular) including the fluids of the thirst center of hypothalamus. The latter, thus, passes nerve impulses to higher brain centers producing the sensation of thirst and active drinking.

It has been shown that animals with distructed rostal hypothalamus increased their water intake (Stevenson et al., 1964). Moreover, warming the preoptic area and rostal hypothalamus of the goats with thermodes ovoked a large increase in water consumption (Andersson, 1971).

About the urine excretion, however, in ruminants the increase in urine excretion under high temperatures was due to an increase in water intake (Kellaway and Colditz, 1975). Moreover, there was a positive correlation between the rise in ambient temperature and each of urine excretion, total vaporization and water intake (Kamal, 1965) had demonstrated that in panting animals exposing to heat lead to a loss of water and $\mathrm{Na}+$ was left behind, however, under very severe conditions, quantities of saliva containing $\mathrm{Na} \div$ might be drooled from the goats mouth and such loss of $\mathrm{Na}+$ amight lead to aldosterone secretion. In addition, the significant diuresis of ruminants at high temperatures may be due to high glutocorticoids, low mineral corticoids and low antidiuretic hormone secretion (Kamal et al., 1962).

Concerning, fecal water output, Schmidt-Nielsen (1964) reported that, since heat caused a decrease in feed consumption, particularly in roughages, a decrease in fecal water output was likely to occur. The same finding were reported by Wilson (1970) and Maloiy and Taylor (1971). Therefore, the results presented in this study concerning fecal water output are in accordance with those obtained by the above investigators. It is worth noting that heat load had a great effect on decreasing fecal water output in goats.

The increase in respiratory water output in response to rise in air temperature has been studied in goats (Maloiy and Taylor, 1971 and Hans and Peter, 1979). When the animals are exposed to beat, some evaporation of water from the mucosa takes place. In spite of the fact that, the temperature of inspired air is high, the mucosa is cooled because the latent heat of vaporization of water is $538 \mathrm{Cal}$ per gram. This is coupled with the fact that air having al ower specific heat that if warms the mucosa very little, results in an efficient cooling of mucosa during inspiration of hot dry air (Walter et al., 1961).

The observed increase in skin water loss under high temperature in this study on goats is in accordance with other studies reported before on cattle (Brody et al., 1955, Kamal et al., 1962, Temor et al., 1969, Moran, 1973, Herz and Steinbaut, 1978) and on sheep (Brook and Siebert, 1960, Alexander, 1961 and Baiely, 1964).

Egypt. J. Anim. Prod. 24, No. 1-2 (1984) 
The increase in cutaneous moisture loss as a response to high temperature to an increase in cutane administration was attributed by Alvarez, et al. (1970) to the sweat glands and blood fiow, which is turn increases the water supply umulation of fluid around the epithe of interstitial fluid in the epiderms. Acca difference in hydrostatic pressurelial cells of the sweat glands, would create pressure (Interstitial space) tosure and flow of water from the site of higher gland).

From the above discussion we have noticed that in mild climate the primary problem for goats is conserving the heat they produ mild climate the by insulative and behavioral adaptation heat they produce, an end achieved as well as the respiratory and skin tation. Urinary and fecal water output because the major heat loss is then water loss had a normal physiological role tion, convection and conduction).

Under hot conditions, fecal water loss was reduced and there was a deone of water output for heat and skin water loss because the problem was over, there was an increase in wation through evaporative channels. Moreto assist somewhat in he in water output through increased urine excretion temperature and excrete it in uripation by cirinking water cooler than body

When the goats were exposed to high temperature, their bodies had a bodies. The water retentionse the goats retained some of water in their their fluids in a normal range for the animals under heat stress to keep maintain normal deep body temperturinuing of physiological process and to water and by its effective evaperature, by virtue of the high specific heat of

\section{References}

Alexander, G. (1961) Temperature regulation in the new-born lemb. II. A climatic respiration chamber for the study of thermoregulation. Aust. J. Agric. Res. 12,1139.

Alvares, M.B., Hahn, L. and Johnson, H.D. (1970) Gutaneous moisture loss in the bovine dating heat exposure and catecholamine infusion. J. Anim. Sci. 30 (1), 95 .

Anders3oil, B.(1971) Thirst and biain control of water balance. Amer. Sci. 59, 408

Baiely, C.B.(1964) Effect of environmental temperature on feed digestion, wates body temperature and certain blood characteristics of fecd digestion, watel metabolicm

Brody, S., Ragsdal, A.C., Yeck, R.G. consumption, and body weight of Jersey and D.(1955) Milk production, feed and water temperature rhythms. Mo. Agr. Exp. Sta. Rolstein cow relation to several ditur :

Brook, A.H. and Siobert, B.F. (1950)

Hans, N.S. and Poter, Aust. J. Asric. Res. 11, 557.

requirements. J. British Soc. Anim. Prod. Anim goat production for covering. protein

Egypt. J. Anim. Prod. 24, No. 1-2 (1984) 
Herz, H. and Steimbart, A. (1978) The reaction of ciomestic animals to beatstress. $J$. of British Soc. Anim. Prod., Arim, Res, and Dev. 7, 1 .

Kamal, T.Y. Johnyon, H.D. and Ragsdale, A.C.(1962) Motabolic reactions during thermal stress $\left(35^{-}-95^{\circ} \mathrm{F}\right)$ in dairy animals acclimated at $50^{\circ} \mathrm{F}$ and $80^{\circ} \mathrm{F}$. Mr. Agric. Ev $\mathrm{F}$. Sta. Res. Bull., 785, pp. 1

Kamal. T.H (1965) physiolorical reactions of cows to hot environmental conditions. Radioisotopes in animal zutrition and physiology. Proc Symp. Prague, Czechoslovakia, Nov, $23-27,1964)$, THEA, Vienna, FP. 767.

Kamal, T.H. and Johson, H.D.(1971) Total body solids loss as a meesure of a short-term heat siress in cattle. J. Anim. Sci. 32 (2), 306.

Kellaway, R.C. and Colditz, P.J.(1975) The effect of heat stress on growth and nitrogen metabolism in Friesiam and Brahman X Friesian heifers. J. Agric. Res. 26, 615.

Malo:y, G.M. and Taylor, C.R.(1971) water requirements of African goats and haird shecp. J. Agric. Sci. 77, 203 ,

Maroiv, G. M.(1972) Rena salt and water excretion in the camel. Symp. Zool. Soc. Lond. 31, 243

Moran, J.\$3. (1973) Heat tolerance of Brahman cross, buffalces, bauterce and shorthcrn steets during expesure to sun and as a result of exeroise. Alst. J. Agric. Res. 24, 775 .

Roy, A., Sengupts, B.P. and Misro, M.S. (1964) Effect of varying envircment of semen a., Sengupts, quality, Cardiorespiratory activity, milk production and Rev. AridZone Res., Paris, Unesco, 24, 275 .

Sohmidt-Nielsen, K. (1964), Desert Animals Physiological Problems of Heat and Water, L.nd. Oxford. Univ. Press, PP. 66.

Snodecor, G.W. and Cachran, W.G.(1967) ,Statistical Methods", 6 th Ed. Iowa State Univ.

Stveneson, J.A.W., Box, B.M. and Lentemurro, D.G. (1964) EviGice of fossible asccciaticx: pathways for theroulation of food and water intakc in the rat. Ccn. J.Physiol. Pharmecol. 42,855 .

Taymour, K.H., Kamar, G.A.M. Gabr, H.A. and \&! Masry, K.M. (1983) Estimaticn of water M.tab 1 lsm in B.eisian cows. Egypt, J. Anim. Prod. (In press).

Tem 9 , O.S., Dhullon, J.S. and Razdan, M.N. (1969) Ind. J. Dairy Sci. 22, 73.

Watter, J.E.C., Wells, R.E. and Merrill, E.W. (1961) Heat and watcr exchange in the respiritory tract. Am. J. Med. 30, 259.

Wilson, A.D. (1970) Water econony and food intake of sheep when water intermitterfly. Aust. J. Agric. Res. 21, 273.

Egypt. J. Anim. Prod. 24, No. 1-2 (1984) 


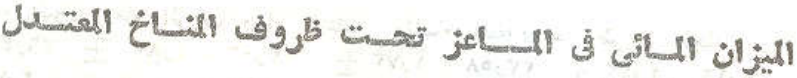

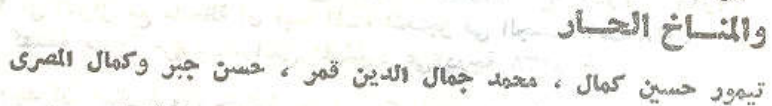

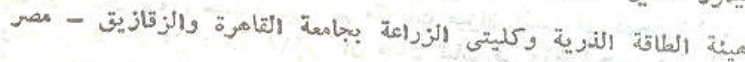

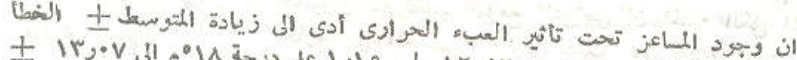

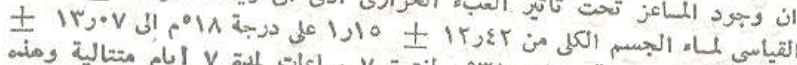

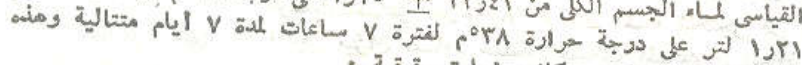

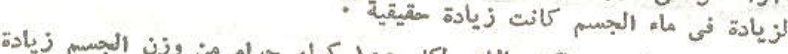

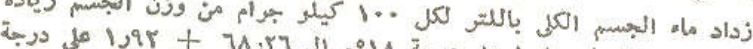

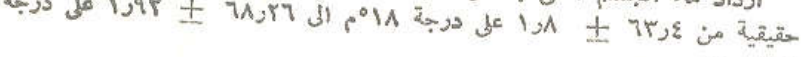

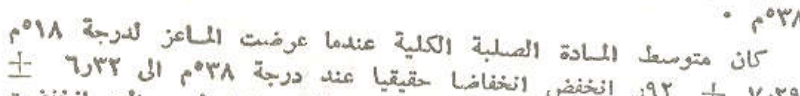

و

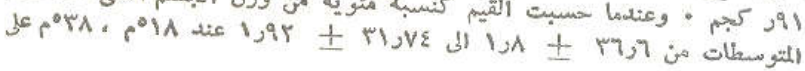

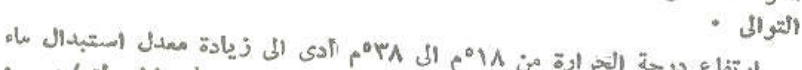

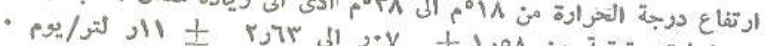

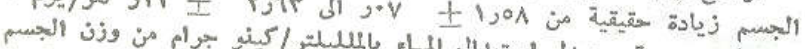

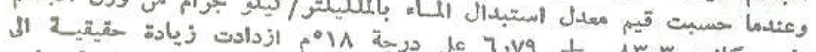
الحي كانت

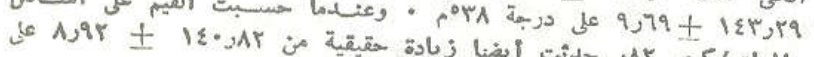

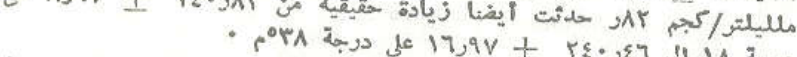

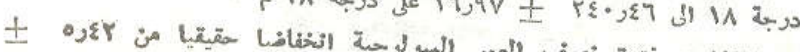

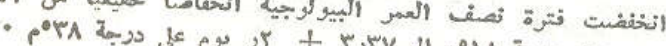

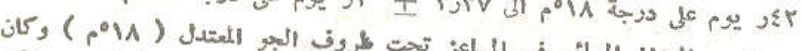

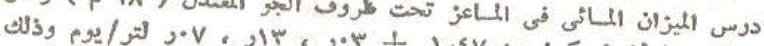

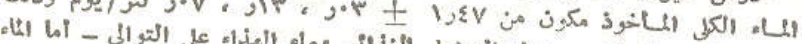

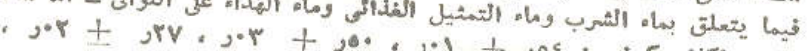

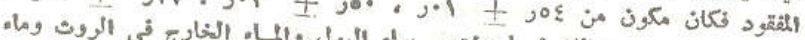

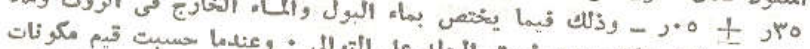

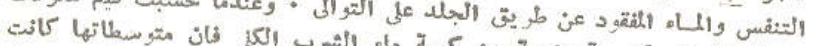

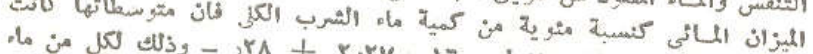

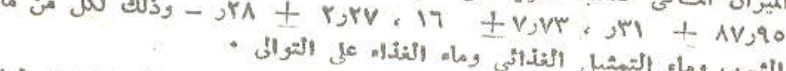

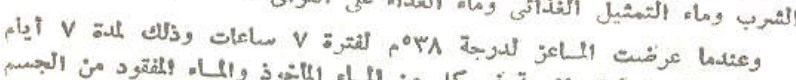

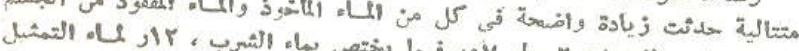

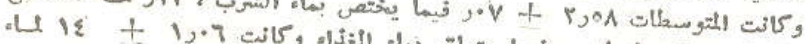

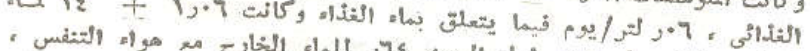

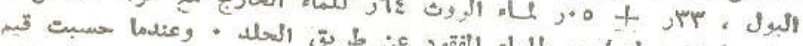

• .

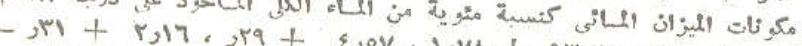

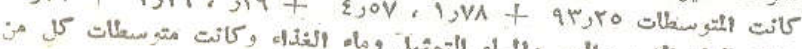

Egypt. J. Anim. Prod. 24, No. 1-2 (1984) 


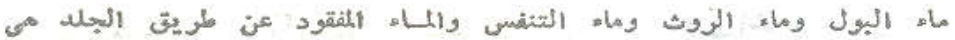

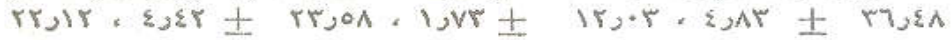

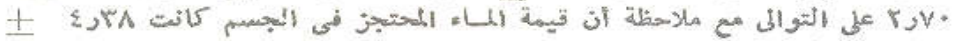

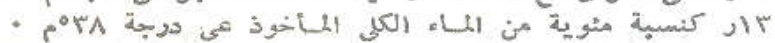

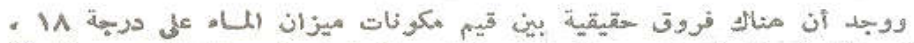
A

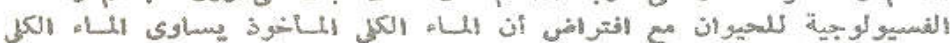

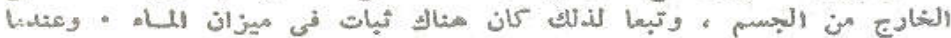

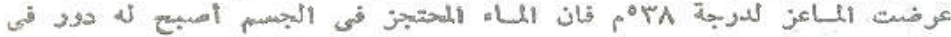

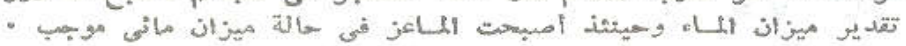

Egypt. J. Anim. Prod. 24, No. 1-2 (1984) 